STUDIES OF HYPOXEMIC/ REOXYGENATION INJURY: WITHOUT AORTIC CLAMPING

III. Comparison of the magnitude of damage by hypoxemia/reoxygenation versus ischemia/reperfusion
The immature heart is more tolerant to ischemia than the adult heart, yet infants with cyanosis show myocardial damage after surgical correction of congenital cardiac defects causing hypoxemia. This study tested the hypothesis that the hypoxemic developing heart is susceptible to oxygen-mediated damage when it is reoxygenated during cardiopulmonary bypass and that this hypoxemic/reoxygenation injury is more severe than ischemic/reperfusion stress. Fifteen Duroc-Yorkshire piglets ( 2 to 3 weeks old, 3 to $5 \mathrm{~kg}$ ) underwent 60 minutes of $37^{\circ} \mathrm{C}$ cardiopulmonary bypass. Five piglets (control) were not made ischemic or hypoxemic. Five underwent 30 minutes of normothermic ischemia (aortic clamping) and 25 minutes of reperfusion before cardiopulmonary bypass was discontinued. Five others underwent 30 minutes of hypoxemia (bypass circuit primed with blood with oxygen tension 20 to $30 \mathrm{~mm} \mathrm{Hg}$ ) and 30 minutes of reoxygenation during cardiopulmonary bypass. Functional (leftventricular contractility) and biochemical (levels of plasma and tissue conjugated dienes and antioxidant reserve capacity) measurements were made before ischemia/hypoxemia and after reperfusion/reoxygenation. Cardiopulmonary bypass (no ischemia or hypoxemia) caused no changes in leftventricular function or coronary sinus levels of conjugated dienes. The tolerance to normothermic ischemia was confirmed, inasmuch as left-ventricular function returned to $108 \%$ of control values and coronary sinus levels of conjugated dienes did not rise after reperfusion. Conversely, reoxygenation raised plasma levels of conjugated dienes in coronary sinus blood in the hypoxic group $57 \%$ compared with end-hypoxic levels $(p<0.05$ versus endhypoxic levels and versus ischemia, by analysis of variance). Antioxidant reserve capacity showed the lowest levels (highest production of malondialdehyde) in the hypoxemic group (51\% higher than control values; $p<0.05$ by analysis of variance). These biochemical changes were associated with a $62 \%$ depression of left-ventricular function after bypass because end-systolic elastance recovered only $38 \%$ of control levels ( $p<0.05$ by analysis of variance). These data confirm the tolerance of the immature heart to ischemia and reperfusion and document a hypoxemic/reoxygenation injury that occurs in immature hearts reoxygenated during bypass. Hypoxemia seems to render the developing heart susceptible to reoxygenation damage that depresses postbypass function and is associated with lipid peroxidation. These findings suggest that starting bypass in cyanotic immature subjects causes an unintended reoxygenation injury that may potentially be counteracted by adding antioxidants to the prime of the extracorporeal circuit. (J THORAC CARDIOVASC SURG 1995;110:1182-9)

Kai Ihnken, MD, ${ }^{a}$ Kiyozo Morita, MD, ${ }^{\text {a }}$ Gerald D. Buckberg, MD, ${ }^{\mathrm{a}}$ Michael P. Sherman, MD, ${ }^{\mathrm{b}}$ and Helen H. Young, $\mathrm{PhD},{ }^{\mathrm{a}}$ Los Angeles, Calif.
From the University of California at Los Angeles School of Medicine, Departments of Surgery ${ }^{\mathrm{a}}$ and Pediatrics, ${ }^{\mathrm{b}}$ Los Angeles, Calif.

Supported in part by the German Research Society (K.I.).

Address for reprints: Gerald D. Buckberg, MD, UCLA Medical Center, Department of Surgery, Division of Cardiothoracic Surgery, B2-375 CHS, 10833 Le Conte Ave., Los Angeles, CA 90024-1741.
Experimental studies indicate the immature heart Eis more tolerant to ischemia and hypoxemia than the adult heart ${ }^{1}$ via a spectrum of protective mechanisms. ${ }^{1-3}$ Hypoxia, simultaneously, depletes natural

Copyright (C) 1995 by Mosby-Year Book, Inc.

$0022-5223 / 95 \$ 5.00+0 \quad \mathbf{1 2 / 0 / 6 1 6 9 5}$ 
cardiac endogenous antioxidant defense mechanisms $^{4,5}$ and therefore may increase vulnerability to the ischemic damage when the aorta is clamped during cardiac repair. Our studies in immature piglets subjected to ventilator hypoxemia show that preischemic hypoxemia limits functional recovery after an otherwise well-tolerated ischemic interval. Unfortunately, asphyxia causes acidosis and functional deterioration resulting in prebypass ischemia. Consequently, the role of subsequent reperfusion injury in the functional depression that follows reoxygenation could not be distinguished from damage caused by the hypoxemia/reoxygenation process.

All prior comparisons of hypoxemia and ischemia were in vitro preparations and we expected ischemia/ reperfusion to be more deleterious than hypoxemia/ reoxygenation because (1) there is better maintenance of tissue glycolysis in hypoxemic models versus ischemic models, ${ }^{6}$ with reduced buildup of tissue lactate and acidosis, and (2) ventricular failure develops more rapidly in ischemic preparations. ${ }^{7}$

This current in vivo study was designed to exclude ischemic influences by producing hypoxemia during cardiopulmonary bypass (CPB), whereby maintenance of systemic pressure and flow in the extracorporeal circuit avoids adverse influences of ischemia. The effects of similar intervals (30 minutes) of hypoxemia/reoxygenation and ischemia/reperfusion are compared to detect whether the immature piglet heart (which is more similar to the human heart) ${ }^{8}$ is tolerant to ischemia and susceptible to hypoxemic/ reoxygenation injury. Confirmation of hypoxemia/ reoxygenation damage without associated ischemic stress would imply that an unintended reoxygenation injury may be imposed when CPB for cardiac repair is begun in cyanotic subjects.

\section{Material and methods}

Preparation. Fifteen healthy Duroc-Yorkshire piglets ( 2 to 3 weeks old, 3 to $5 \mathrm{~kg}$ ) were premedicated with diazepam $0.5 \mathrm{mg} / \mathrm{kg}$ intramuscularly and anesthetized with sodium pentobarbital $(30 \mathrm{mg} / \mathrm{kg}$ intraperitoneally); anesthesia was maintained by intermittent $5 \mathrm{mg} / \mathrm{kg}$ pentobarbital bolus intravenous injections. All animals received humane care in compliance with the "Principles of Laboratory Animal Care" formulated by the National Society for Medical Research and the "Guide for the Care and Use of Laboratory Animals" prepared by the National Academy of Sciences and published by the National Institutes of Health (NIH Publication No. 86-23, revised 1985). The experimental preparation, including cannulation for bypass and blood sample procurement, is comparable to that described previously.

\section{Measurements}

Hemodynamics. Measurements were made before CPB was started (control) and 15 and 30 minutes after $C P B$ was discontinued. Arterial blood gas, electrolyte, and hemoglobin measurements were made by the Blood Gas System 228 (Ciba-Corning, Medfield, Mass.). Final tissue biochemical measurements were made 30 minutes after discontinuation of CPB from biopsy specimens in hearts arrested with $4^{\circ} \mathrm{C}$ blood cardioplegic solution $(30 \mathrm{mEq} / \mathrm{kg}$ $\mathrm{KCl})$ to stop metabolism. Blood samples to determine levels of conjugated dienes were taken from the coronary sinus before extracorporeal circulation was started (control) before hypoxemia or ischemia, 5 minutes after hypoxemia or ischemia, at the end of hypoxemia, 5 minutes after reperfusion/reoxygenation, and before CPB was discontinued and at the end of the observation period.

Left ventricular (LV) performance was evaluated by inscribing pressure volume loops with use of an LV five-electrode conductance catheter as described previously, ${ }^{9}$ and cardiac output was determined by duplicate injections of $1 \mathrm{ml}$ of $4^{\circ} \mathrm{C}$ saline solution into the right atrium through a thermodilution probe placed into the main pulmonary artery and connected to a cardiac computer (Model 9520A, American Edwards Laboratory, Santa Ana, Calif.). Results were expressed as stroke work index in grams times meters per kilogram to normalize for body weight.

Myocardial conjugated dienes. The level of conjugated dienes, a marker of lipid peroxidation, was determined from LV endocardial biopsy specimens and from coronary blood samples as described previously. ${ }^{10}$

Antioxidant reserve capacity. The method of Godin, Ko, and Garnett ${ }^{11}$ was used to assess the vulnerability of hypoxic reoxygenated myocardium to subsequent oxidant stress as determined previously.

Each heart was examined after death to ensure satisfactory ligation of the ductus and absence of the patent foramen ovale.

Experimental groups. All piglets underwent 60 minutes of CPB, followed by a 30-minute interval of observation after CPB.

$C P B$ without hypoxemia or ischemia (control). Five piglets underwent CPB for 1 hour without hypoxemia or ischemia.

Hypoxemia/reoxygenation during $C P B$. Five piglets underwent 30 minutes of hypoxemia during $C P B$, which was imposed by reducing inspired oxygen fraction by adding $\mathrm{N}_{2}$ to the gas mixture to lower oxygen tension $\left(\mathrm{Po}_{2}\right)$ in the extracorporeal circuit to 20 to $30 \mathrm{~mm} \mathrm{Hg}$. Hypoxemia was maintained for 30 minutes and followed by 30 minutes of reoxygenation during $\mathrm{CPB}$ at $\mathrm{PO}_{2}$ approximately $400 \mathrm{~mm}$ $\mathrm{Hg}$.

Ischemialreperfusion during $C P B$. Five other piglets underwent 30 minutes of normothermic ischemia during CPB imposed by clamping the aorta 5 minutes after CPB was started. Reperfusion was done during CPB for 25 minutes before extracorporeal circulation was stopped.

All piglets were observed for 30 minutes after CPB, at which time final hemodynamic and biochemical measurements were made. 


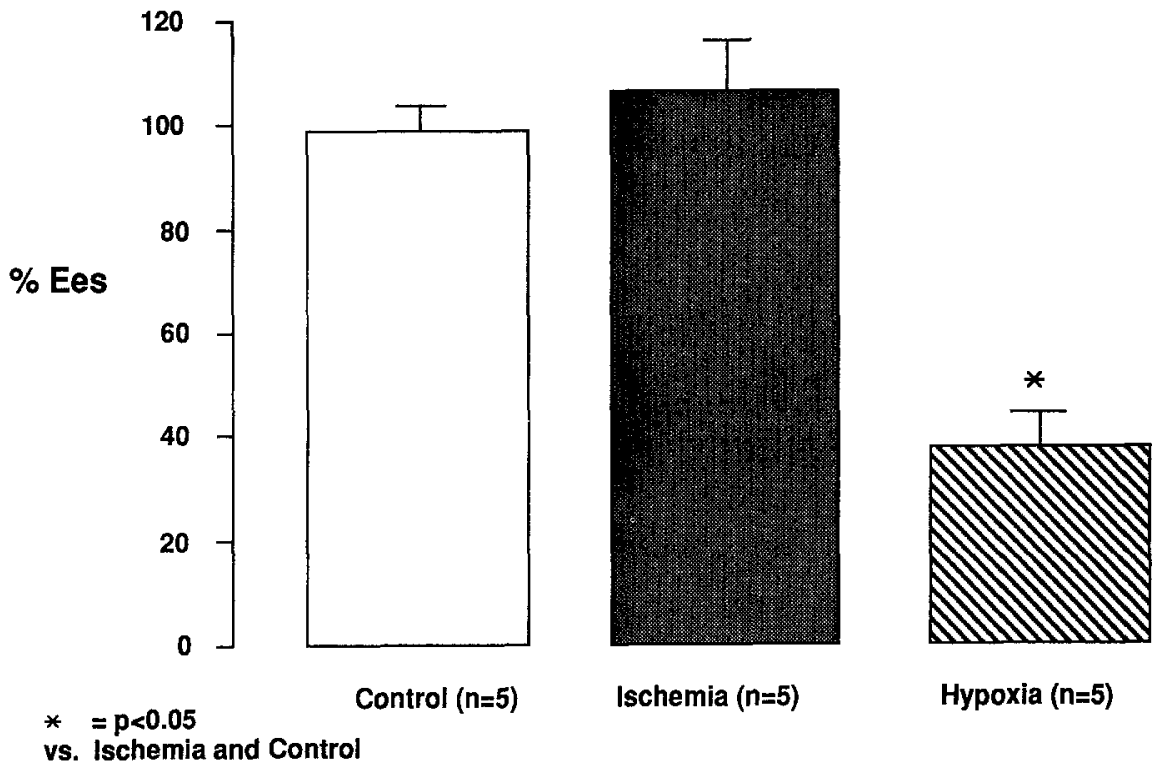

Fig. 1. Cardiac contractility evaluated by inscribing pressure volume loops to evaluate end-systolic elastance (Ees), expressed as percent of control values (see text for description).

Table I. Hemodynamic data during $C P B$

\begin{tabular}{|c|c|c|c|c|c|c|c|c|c|}
\hline \multirow[b]{2}{*}{ Parameters } & \multicolumn{3}{|c|}{ Control $(n=5)$} & \multicolumn{3}{|c|}{ Ischemia $(n=5)$} & \multicolumn{3}{|c|}{ Hypoxia $(n=5)$} \\
\hline & $5 \mathrm{~min}$ & $30 \mathrm{~min}$ & $60 \mathrm{~min}$ & $5 \min$ & $30 \mathrm{~min}$ & $60 \mathrm{~min}$ & $5 \min$ & $30 \mathrm{~min}$ & $60 \mathrm{~min}$ \\
\hline MAP (mm Hg) & $54.4 \pm 2.2$ & $62.2 \pm 3.2$ & $65.2 \pm 3.7$ & $52.6 \pm 1.1$ & $63.2 \pm 7.6$ & $56.2 \pm 3.2$ & $53.4 \pm 1.9$ & $55.8 \pm 3.9$ & $59.4 \pm 3.3$ \\
\hline $\begin{array}{l}\text { Pump flow index } \\
(\mathrm{ml} / \mathrm{kg} / \mathrm{min})\end{array}$ & $116 \pm 14$ & $93 \pm 9$ & $90 \pm 8$ & $107 \pm 10$ & $92 \pm 17$ & $77 \pm 5$ & $150 \pm 18$ & $126 \pm 21$ & $111 \pm 20$ \\
\hline $\begin{array}{l}\text { SVRI }(\mathrm{mm} \mathrm{Hg} \cdot \min \cdot \\
\left.\mathrm{L}^{-1} \cdot \mathrm{kg}\right)\end{array}$ & $499 \pm 64$ & $703 \pm 81$ & $759 \pm 96$ & $512 \pm 58$ & $828 \pm 230$ & $746 \pm 90$ & $382 \pm 59$ & $530 \pm 151$ & $621 \pm 127$ \\
\hline
\end{tabular}

Table II. Hemodynamic data before and 30 minutes after $C P B$

\begin{tabular}{|c|c|c|c|c|c|c|}
\hline \multirow[b]{2}{*}{ Parameters } & \multicolumn{2}{|c|}{ Control $(n=5)$} & \multicolumn{2}{|c|}{ Ischemia $(n=5)$} & \multicolumn{2}{|c|}{ Hypoxia $(n=5)$} \\
\hline & Before $C P B$ & 30 min after $C P B$ & Before $C P B$ & 30 min after $C P B$ & Before $C P B$ & 30 min after $C P B$ \\
\hline MAP (mm Hg) & $69.8 \pm 5.3$ & $58.6 \pm 3.6$ & $63.4 \pm 6.7$ & $63.4 \pm 6.9$ & $68.6 \pm 2.3$ & $60.0 \pm 7.1$ \\
\hline Heart rate (beats/min) & $226 \pm 9$ & $255 \pm 10$ & $219 \pm 7$ & $222 \pm 7$ & $202 \pm 4$ & $212 \pm 7$ \\
\hline Cardiac index $(\mathrm{ml} / \mathrm{kg} / \mathrm{min})$ & $114 \pm 18$ & $92 \pm 8$ & $105 \pm 8$ & $85 \pm 11$ & $112 \pm 8$ & $74 \pm 7^{*}$ \\
\hline LVSWI $(\mathrm{g} \cdot \mathrm{m} / \mathrm{kg})$ & $0.47 \pm 0.06$ & $0.36 \pm 0.03$ & $0.38 \pm 0.07$ & $0.35 \pm 0.03$ & $0.49 \pm 0.06$ & $0.25 \pm 0.03^{*}$ \\
\hline SVRI $\left(\mathrm{mm} \mathrm{Hg} \cdot \min \cdot \mathrm{L}^{-1} \cdot \mathrm{kg}\right)$ & $676 \pm 117$ & $729 \pm 55^{-}$ & $593 \pm 30$ & $915 \pm 156$ & $621 \pm 28$ & $863 \pm 158$ \\
\hline
\end{tabular}

LVSWI, Left ventricular stroke work index.

" $p<0.05$ versus before CPB.

Statistical analyses. Data were analyzed with use of the Stat View 2.0 program (Abacus Concepts, Inc., Berkeley, Calif.) on a MacIntosh IIci computer (Apple Inc., Cupertino, Calif.). Analysis of variance was used for intergroup comparison and the Student's $t$ test was used for comparison of repeated variables within experimental groups. ${ }^{12}$ Differences were considered significant at a probability level of $p<0.05$. Group data were expressed as mean plus or minus the standard error of the mean.

\section{Results}

Hemodynamics. Mean aortic pressure (MAP) and heart rate were comparable between groups before, during, and after CPB, because extracorpo- 


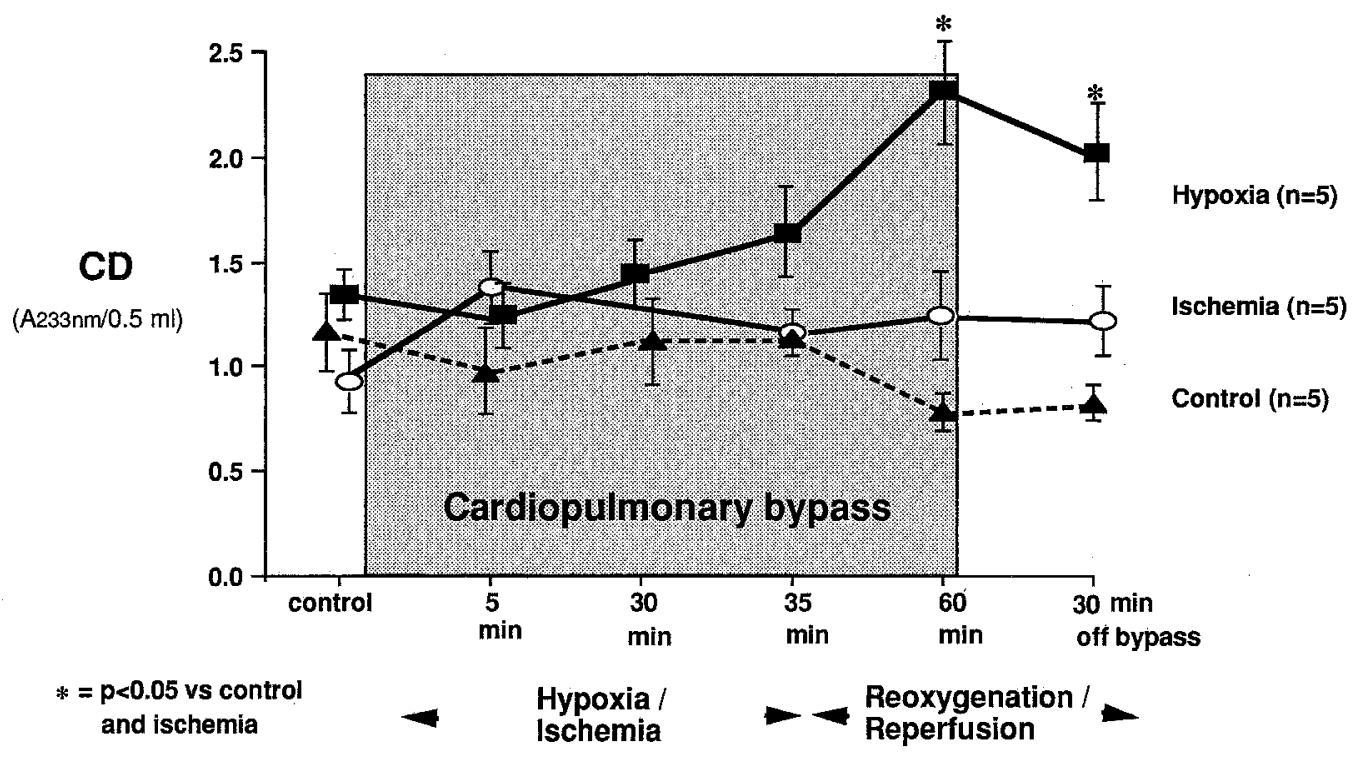

Fig. 2. Levels of conjugated dienes $(C D)$ sampled from coronary sinus blood during control period, during ischemia hypoxemia, and after reperfusion and reoxygenation (see text for description). $A$, Absorbance.

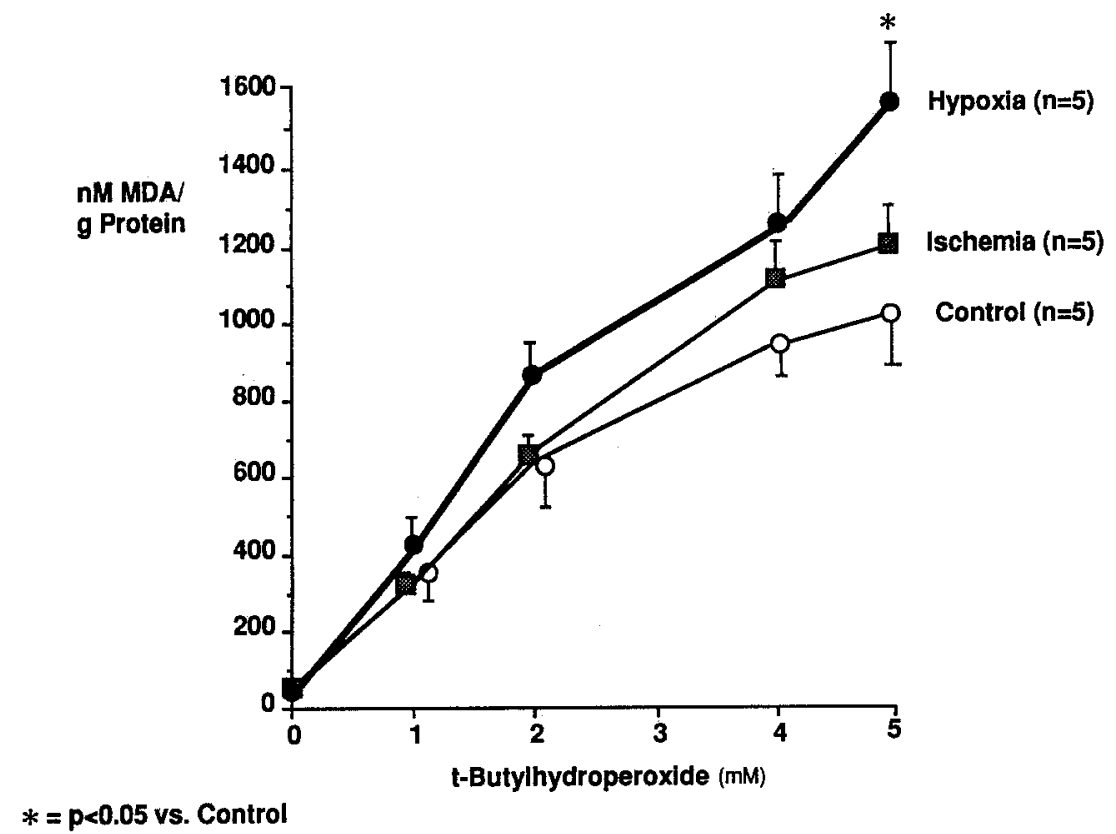

Fig. 3. Antioxidant reserve capacity in LV subendocardial muscle, evaluated after 30-minute observation period after CPB was discontinued (see text for description). $M D A$, Malondialdehyde.

real flow rate was controlled to keep MAP at 50 to $60 \mathrm{~mm} \mathrm{Hg}$. Systemic vascular resistance index (SVRI) was lowered during CPB in hypoxic piglets as the extracorporeal flow rate was raised approximately $30 \%$ to maintain arterial pressure at 50 to $60 \mathrm{~mm} \mathrm{Hg}$ (Table I). SVRI increased in all piglets after CPB and reached the highest levels in piglets subjected to ischemia/reperfusion, but these differences did not reach statistical significance.

LV performance, expressed as end-systolic elastance, recovered completely in control studies and 
after ischemia/reperfusion (Fig. 1), and postbypass cardiac index and stroke work index also returned to prebypass levels (Table II). In contrast, contractility was depressed severely $(70 \%$ versus ischemia, $62 \%$ versus control) after hypoxemia/reoxygenation compared with ischemia/ reperfusion studies and control values $(p<0.05)$. Cardiac index and stroke work index were lowered $33 \%$ and $49 \%$, respectively, below levels before CPB $(p<0.05)$.

Biochemical. Coronary sinus conjugated diene levels remained unchanged in control and in hypoxemia/ischemia reperfusion studies, whereas coronary sinus conjugated diene levels rose $38 \%$ ( $p<$ 0.05 ) during reoxygenation in piglets and remained elevated after CPB (Fig. 2). Myocardial tissue levels of conjugated dienes were unchanged at the time final analyses were made 30 minutes after CPB was discontinued in all studies. Myocardial antioxidant reserve capacity was reduced most severely by hypoxemia/reoxygenation, inasmuch as cardiac muscle from this group incubated with 0 to $5 \mathrm{mmol} / \mathrm{L}$ $t$-butylhydroperoxide produced $56 \%$ more malondialdehyde than muscle from the control group and $46 \%$ more than that from the ischemia/reperfusion group (Fig. 3, $p<0.05$ ).

\section{Discussion}

This study of intact immature piglets undergoing similar 30-minute intervals of ischemia and hypoxemia during CPB (1) shows that extracorporeal circulation per se produces no biochemical or functional cardiac changes, (2) confirms the tolerance of the infantile heart to ischemia, and (3) documents impaired functional recovery with associated signs of lipid peroxidation after reoxygenation after hypoxemia.

The observed biochemical and functional recovery of the immature heart after an ischemic interval that causes significant damage in the adult porcine myocardium ${ }^{13}$ may be the result of several adaptive mechanisms including increased glycolysis, ${ }^{1}$ substrate-level phosphorylation, ${ }^{2}$ low levels of $5^{\prime}$-nucleotidase, ${ }^{3}$ and increased mitochondrial activity. ${ }^{14}$ The ischemic tolerance of the intact immature piglet heart confirms findings in puppies. ${ }^{15}$ These data add the information that lipid peroxidation does not follow reperfusion, because levels of conjugated dienes remain relatively normal, presumably by slight expenditure of antioxidant reserve capacity (Fig. 3). Conversely, the same 30-minute hypoxemic interval caused severe postreoxygenation depletion of endogenous antioxidant reserve capacity, lipid peroxidation, and substantial functional impairment. We presume the oxidant damage after reoxygenation increases susceptibility to subsequent ischemic stress (i.e., aortic clamping needed for surgical repair) and may contribute to the increased ischemic vulnerability reported in experimental studies of chronic cyanosis. ${ }^{16,17}$

The finding that hypoxemia/reoxygenation produced more biochemical and functional damage than a comparable period of ischemia/reperfusion was unexpected, because we anticipated more injury after ischemia/reperfusion caused by buildup of lactate and acidosis, with subsequent impaired adenosine triphosphate production. Rovetto, Whitmer and Neely ${ }^{6}$ report $50 \%$ more energy production during hypoxemia than during ischemia and suggest a more favorable biochemical environment during hypoxemia because of washout of metabolic end products of anaerobiosis, coupled with the continuous provision of substrate.

To our knowledge, this is the first comparison of hypoxemia/reoxygenation with ischemia/reperfusion in the in vivo heart, so the model itself may have introduced heretofore unevaluated variables. Previous reports of hypoxemia versus ischemia used the isolated heart model, whereby $\mathrm{O}_{2}$ delivery is fixed either by maintaining flow and reducing $\mathrm{Po}_{2}$ (hypoxemia) or reducing flow and maintaining $\mathrm{PO}_{2}$ (ischemia). These conditions may inadvertently blend ischemia and hypoxemia, because hypoxemic vasodilation lowers coronary perfusion pressure ${ }^{18}$ and may cause nonhomogeneous oxygen delivery. The hypoxemia/reoxygenation model with the use of $\mathrm{CPB}$ was selected to ensure a standard hypoxemic interval under controlled conditions in the intact neonatal piglet, which is more similar to the human than other animal models (rat, rabbit, dog). ${ }^{8}$ The myocardial response to hypoxemia is characterized by increased calcium-activated diastolic tension with increased chamber stiffness ${ }^{19}$ and washout of acid metabolites that can impair continued glycolysis, whereas the converse occurs with ischemia. ${ }^{6,18}$

Differences in the energy supply/demand balance may be an important factor accounting for the different responses to ischemia/reperfusion and hypoxemia/reoxygenation, because heart rate falls with ischemia (i.e., low flow) and the heart stops contracting when the aorta is clamped. Conversely, tachycardia persists to maintain higher oxygen demands in the hypoxemic model, especially when perfusion pressure is maintained. We suspect that 
avoidance of hypotension during hypoxemic vasodilation (by increasing extracorporeal circuit flow rate) maintained more homogeneous perfusion, so that regional inequalities in perfusion are an unlikely explanation for the more detrimental effects of hypoxemia than of ischemia. The effects of heart rate in accentuating hypoxemic versus ischemic damage was addressed by Serizawa and associates, ${ }^{18}$ and their observations were reinforced by Jarmakani and colleagues, ${ }^{20}$ who observed good functional recovery in hypoxemic hearts paced at a slow rate (30 beats/min). A more valid comparison of hypoxemia and ischemia in vitro would require pacing to maintain heart rate at comparable levels under both conditions.

Ischemia differs from hypoxemia also in relation to the accumulation of lactate for anaerobic metabolism, because normal to increased perfusion prevails during hypoxemia and washes away the end products of anaerobiosis. Lactate buildup may provide a readily available source of reducing equivalents that limit reoxygenation damage on reintroduction of molecular oxygen. Kowalski and associates $^{21}$ showed that lactate protects anoxic hepatocytes against oxidant stress in a dose-dependent manner, and this observation was confirmed by Altschuid, Hostetler, and Brierly, ${ }^{22}$ who exposed isolated myocytes to acidosis in studies of hypoxemia/reoxygenation.

The factors responsible for increased tolerance to ischemia notwithstanding, these short-term studies provide some biochemical insight into the reported increased susceptibility of the cyanotic heart to ischemic damage during the aortic clamping required when congenital defects causing cyanosis are repaired, as reported in chronically cyanotic hearts by Fujiwawa ${ }^{17}$ and Silverman ${ }^{16}$ and their associates and documented clinically by Del Nido and colleagues. ${ }^{23}$ Our findings of reduced tissue antioxidant reserve capacity and elution of markers of lipid peroxidation after reoxygenation are consistent with those in the clinical reports of $\mathrm{Teoh}^{24}$ and Del $\mathrm{Nido}^{25}$ and their colleagues in patients with tetralogy of Fallot.

Most biochemical evidence of oxidant damage was derived from coronary sinus blood sampled during reoxygenation, and tissue levels of conjugated dienes (the selected marker for lipid peroxidation) were normal 30 minutes after CPB was discontinued. These tissue findings are consonant with those of another study showing an increased tissue level of conjugated dienes only during rein- troduction of molecular oxygen, with return to normal after CPB was discontinued in the ischemia/ reperfusion model. ${ }^{26}$ We did not sample the myocardium during reoxygenation and suspect that any conjugated dienes that accumulated were washed out during the 60-minute interval after reintroduction of molecular oxygen.

We ascribe the mechanism of oxidant damage after hypoxemia/reoxygenation to a burst of oxygen radical production after reintroduction of molecular oxygen that overwhelmed the scavenging capacity of the reduced cellular defenses. ${ }^{4,5}$ This notion is based partially on the beneficial effects of antioxidants reported by others ${ }^{27,28}$ and confirmed in our recent study ${ }^{28 a}$ in which an intravenous metabolic support solution containing antioxidants reduced reoxygenation injury. This study does not address the biochemical pathway of oxidant injury, which may include leukocytes, ${ }^{29}$ the arachidonic pathway, ${ }^{30}$ and production of xanthine metabolites. ${ }^{31}$ The role of the xanthine oxidase-hypoxanthine pathway has been thought previously to play an unimportant part in oxidant damage to the porcine heart because of the reported lack of xanthine oxidase in the human and pig. Isolated heart models, however, failed to account for xanthine oxidase that may arise in other organs (kidney, liver, gut) and reach the myocardium via the bloodstream in the in vivo condition, ${ }^{32}$ as in this study.

Our study also does not distinguish which aforementioned mechanism renders the immature heart more susceptible to hypoxemia/reoxygenation damage than to ischemia/reperfusion damage, but rather emphasizes that a reoxygenation injury occurs when hyperoxic CPB is begun in the cyanotic heart. This reoxygenation damage occurs independent of ischemia and therefore underscores the possibility of the increased susceptibility of the hypoxemic myocardium to subsequent ischemic injury. The spectrum of changes following reoxygenation after hypoxemia are similar to those following reperfusion, ${ }^{5,33,34}$ so that interventions that limit reperfusion damage, including antioxidants, may be used to limit reoxygenation injury, inasmuch as the process of reoxygenation, including the adjustment of the composition of the fluid in the extracorporeal circulation and $\mathrm{PO}_{2}$, can be controlled intraoperatively. Consequently, the possibility exists that, like reperfusion damage, reoxygenation injury can be limited in the surgical setting during correction of mechanical defects causing cyanosis. 


\section{REFERENCES}

1. Jarmakani JM, Nagatomo T, Nakazawa M, Langer GA. Effect of hypoxia on myocardial high-energy phosphates in the neonatal mammalian heart. Am J Physiol 1978;235:H475-81.

2. Julia PL, Young HH, Buckberg GD, Kofsky ER, Bugyi HI. Studies of myocardial protection in the immature heart. II. Evidence for importance of amino acid metabolism in tolerance to ischemia. J THORAC Cardiovasc Surg 1990;100:888-95.

3. Bolling SF, Olszanski DA, Bove EL, Childs KF. Enhanced myocardial protection during global ischemia with 5 '-nucleotidase inhibitors. J THORAC CARDIOVASC SURG 1992;103:73-7.

4. Gauduel Y, Duvelleroy MA. Role of oxygen radicals in cardiac injury due to reoxygenation. J Mol Cell Cardiol 1984;16:459-70.

5. Guarnieri C, Flamigni F, Caldarera CM. Role of oxygen in the cellular damage induced by reoxygenation of hypoxic heart. J Mol Cell Cardiol 1980;12:797-808.

6. Rovetto MJ, Whitmer JT, Neely JR. Comparison of the effects of anoxia and whole heart ischemia on carbohydrate utilization in isolated working rat hearts. Circ Res 1973;32:699-704.

7. Allen DG, Orchard CH. Myocardial contractile function during ischemia and hypoxia. Circ Res 1987;60: 153-68.

8. Swindle MM. Porcine models in surgical research: an overview. In: Tumbleson ME, ed. Swine in biomedical research. 1st ed. New York: Plenum Press, 1986:23541.

9. Teitel DF, Klautz R, Steenduk P, Van der Velde ET, Van Bel F, Baan J. The end-systolic pressure-volume relationship in the newborn lamb: effects of loading and inotropic interventions. Pediatr Res 1991;29:473-82.

10. Lesnefsky EJ, Fennessey PM, Van Benthuysen KM, McMurtry IF, Travis VL, Horwitz LD. Superoxide dismutase decreases early reperfusion release of conjugated dienes following regional canine ischemia. Basic Res Cardiol 1989;84:191-6.

11. Godin DV, Ko KM, Garnett ME. Altered antioxidant status in the ischemic/reperfused rabbit myocardim: effects of allopurinol. Can J Cardiol 1989;5:365-71.

12. Godfrey K. Comparing the means of several groups (statistics in practice). N Engl J Med 1985;313:145060.

13. Krukenkamp IB, Levitsky S. Myocardial oxygen consumption after fibrillation in the nonhypertrophied porcine ventricle. Ann Thorac Surg 1991;52:949-54.

14. Park CD, Mela L, Wharton R, Reilly J, Fishbein P, Aberdeen E. Cardiac mitochondrial activity in acute and chronic cyanosis. J Surg Res 1973;14:139-46.

15. Julia PL, Kofksy ER, Buckberg GD, Young HH, Bugyi HI. Studies of myocardial protection in the immature heart. I. Enhanced tolerance of immature vs adult myocardium to global ischemia with refer- ence to metabolic differences. J THORAC CARDIOVASC SURG 1990;100:879-87.

16. Silverman NA, Kohler J, Levitsky S, Pavel DG, Fang RB, Feinberg $H$. Chronic hypoxemia depresses global ventricular function and predisposes to depletion of high energy phosphates during cardioplegic arrest: implications for surgical repair of cyanotic congenital heart defects. Ann Thorac Surg 1984;37:304-8.

17. Fujiwara T, Kurtts T, Anderson W, Heinle J, Mayer JE Jr. Myocardial protection in cyanotic neonatal lambs. J Thorac Cardiovasc Surg 1988;96:700-10.

18. Serizawa T, Vogel WM, Apstein CS, Grossman W. Comparison of acute alterations in left ventricular relaxation and diastolic chamber stiffness induced by hypoxia and ischemia. J Clin Invest 1981;68:91102.

19. Wexler LF, Weinberg EO, Ingwall JS, Apstein CS. Acute alterations in diastolic left ventricular chamber distensibility: mechanistic differences between hypoxemia and ischemia in isolated perfused rabbit and rat hearts. Circ Res 1986;59:515-28.

20. Jarmakani JM, Nakazawa M, Nagatomo T, Langer GA. Effect of hypoxia on mechanical function in the neonatal mammalian heart. Am J Physiol 1978;235: H469-74.

21. Kowalski DP, Aw TY, Park Y, Jones DP. Postanoxic oxidative injury in rat hepatocytes: lactate-dependent protection against tert-butylhydroperoxide. Free Radic Biol Med 1992;12:205-12.

22. Altschuld RA, Hostelter JR, Brierly GP. Response of isolated rat heart cells to hypoxia, reoxygenation and acidosis. Circ Res 1981;49:307-16.

23. Del Nido PJ, Mickle DAG, Wilson GJ, et al. Inadequate myocardial protection with cold cardioplegic arrest during repair of tetralogy of Fallot. J THORAC Cardiovasc Surg 1988;95:223-9.

24. Teoh KH, Mickle DAG, Weisel RD, Li R, Tumiati LC, Coles JG, Williams WG. Effect of oxygen tension and cardiovascular operations on the myocardial antioxidant enzyme activities in patients with tetralogy of Fallot and aorta-coronary bypass. J THORAC CARDIOVASC SuRG 1992;104:159-64.

25. Del Nido PJ, Mickle DAG, Wilson GJ, et al. Evidence of myocardial free radical injury during elective repair of tetralogy of Fallot. Circulation 1987;76(Suppl): V174-9.

26. Romaschin AD, Rebeyka I, Wilson GJ, Mickle DAG. Conjugated dienes in ischemic and reperfused myocardium: an in vivo chemical signature of oxygen free radical mediated injury. J Mol Cell Cardiol 1987;19: 289-302.

27. Downey JM, Omar B, Ooiwa H, McCord J. Superoxide dismutase therapy for myocardial ischemia. Free Radic Res Commun 1991;12-13:703-20.

28. Bolli R, Jeroudi MO, Patel BS, et al. Marked reduc- 
tion of free radical generation and contractile dysfunction by antioxidant therapy begun at the time of reperfusion. Circ Res 1989;65:607-22.

28a. Julia PL, Young HH, Buckberg GD, Kofsky ER, Bugyi HI. Studies of myocardial protection in the immature heart. IV. Improved tolerance of immature myocardium to hypoxia and ischemia by intravenous metabolic support. J Thorac Cardiovasc Surg 1991;101:23-32.

29. Simpson PJ, Mickelson JK, Lucchesi BR. Free radical scavengers in myocardial ischemia. Fed Proc 1987;46: 2413-21.

30. Kukreja RC, Kontos HA, Hess ML, Ellis EF. PGH synthase and lipoxygenase generate superoxide in the presence of NADH or NADPH. Circ Res 1986;59: 612-9.
31. McCord JM. Oxygen-derived free radicals in postischemic tissue injury. N Engl J Med 1985;312:15963.

32. Saugstad OD. Hypoxanthine as an indicator of hypoxia: its role in health and disease through free radical production. Pediatr Res 1988;23:143-50.

33. Kraemer R, Mullane KM. Neutrophils delay functional recovery of the post-hypoxic heart of the rabbit. J Pharmacol Exp Ther 1989;251:620-6.

34. Hearse DJ, Humphrey SM, Chain EB. Abrupt reoxygenation of the anoxic potassium-arrested perfused rat heart: a study of myocardial enzyme release. J Mol Cell Cardiol 1973;5:395-407. 